\title{
Embryonal carcinoma of testis simulating seminoma
}

\author{
JOAN M ALDERDICE, * S R JOHNSTON† \\ From the Departments of ${ }^{*}$ Histopathology and $\nmid U r o l o g y$, Belfast City Hospital, Belfast, Northern Ireland
}

SUMMARY The clinical and pathological features of two patients with testicular germ cell tumour are described. The cases illustrate the area of gross and histological overlap between seminoma and solid embryonal carcinoma, for which there are useful distinguishing features which might aid diagnosis.

Teratoma and seminoma of the testis may occur as separate pure tumours or together in a combined germ cell tumour. Both malignancies are thought to originate from totipotential germ cells. ${ }^{1}$ The histological patterns of the two neoplasms are usually quite distinct, but occasionally, problems arise in distinguishing embryonal carcinoma (malignant teratoma undifferentiated) from seminoma.

This paper describes the clinical and pathological features of two patients, each of whom had a testicular germ cell tumour showing histological features usually associated with seminoma, but which on further study proved to be cases of embryonal carcinoma. The histological distinction is very important as the behaviour and treatment of embryonal carcinoma is more aggressive; and the prognosis more guarded.

\section{Case reports}

CASE 1

This 25 year old man was originally admitted to hospital in January 1983 with a one week history of umbilical pain, aching in both loins, and insomnia. He had no history of injury. Examination showed that he had a hydrocoele and slight gynaecomastia. He was treated with antibiotics for epididymoorchitis, but when his condition did not settle, the testis was surgically explored in June and a left orchidectomy performed. Preoperative $\alpha$-fetoprotein (AFP) was $9000 \mathrm{U} / 1$ and B human chorionic gonadotrophin (BHCG) was $8193 \mathrm{U} / 1$.

CASE 2

This 27 year old patient presented in October 1985 having noticed a discomfort in the scrotum after lift- ing a heavy weight three weeks previously. He also complained of discomfort on walking and playing rugby. No history of direct trauma was noted. On examination, the right testis was enlarged and firm but not tender. No other abnormality was noticed on full physical examination. Chest $x$-ray yielded normal results. Preoperative AFP was $50000 \mathrm{U} / 1$ and BHCG $113 \mathrm{U} / \mathrm{l}$. Right orchidectomy was performed through a right suprainguinal incision.

\section{Methods}

Both specimens were received in $4 \%$ aqueous formalehyde and blocks were selected, nine from case 1 (the larger tumour) and eight from case 2. The tissue was secondarily fixed in Helly's fluid, $\left(1000 \mathrm{~cm}^{3}\right.$ distilled water, $25 \mathrm{~g}$ potassium dichromate, $50 \mathrm{~g}$ mercuric chloride and $50 \mathrm{~cm}^{3}$ of $40 \%$ formaldehyde), followed by processing to paraffin wax.

The staining methods used were haematoxylin and eosin and periodic acid Schiff with and without diastase pretreatment. Indirect immunoperoxidase methods were used to show BHCG, AFP, carcinoembryonic antigen (CEA) and cytokeratin. ${ }^{2}$ BHCG, AFP, and CEA antisera were obtained from Dako Ltd, and cytokeratin antiserum came from Labsystems, (PKK1, decorate cytokeratin proteins of $46,52$ and $54 \mathrm{kD})$.

\section{Pathology}

CASE 1

The surgical specimen weighed $140 \mathrm{~g}$. The testis was replaced by a $7 \times 4 \times 3 \mathrm{~cm}$ greyish neoplasm, which had spread to the rete testis. No cystic or haemorrhagic areas were noted.

Histological examination showed a germ cell tumour set in a striking fibrous stroma which contained abundant lymphocytes, numerous Langhans' giant cells, and occasional ill defined epitheloid gran- 
ulomata (fig 1). The malignant cells had well demarcated borders and were arranged in sheets and clusters, as in a typical seminoma (fig 2 ), but acinar and papillary arrangements more typical of embryonal carcinoma were also present (fig 3). The cells were large with prominent nucleoli and pale, slightly granular cytoplasm. They exhibited pleomorphism, and five mitoses could be counted per high power field.

The periodic acid Schiff technique failed to show any glycogen in the tumour cells, but immunohistochemical staining showed small clusters of CEA positive malignant cells, The cytokeratin, AFP, and BHCG stains were negative.

\section{CASE 2}

The orchidectomy specimen weighed $110 \mathrm{~g}$. The testis measured $6.5 \times 5 \times 5 \mathrm{~cm}$ and contained a $4 \mathrm{~cm}$

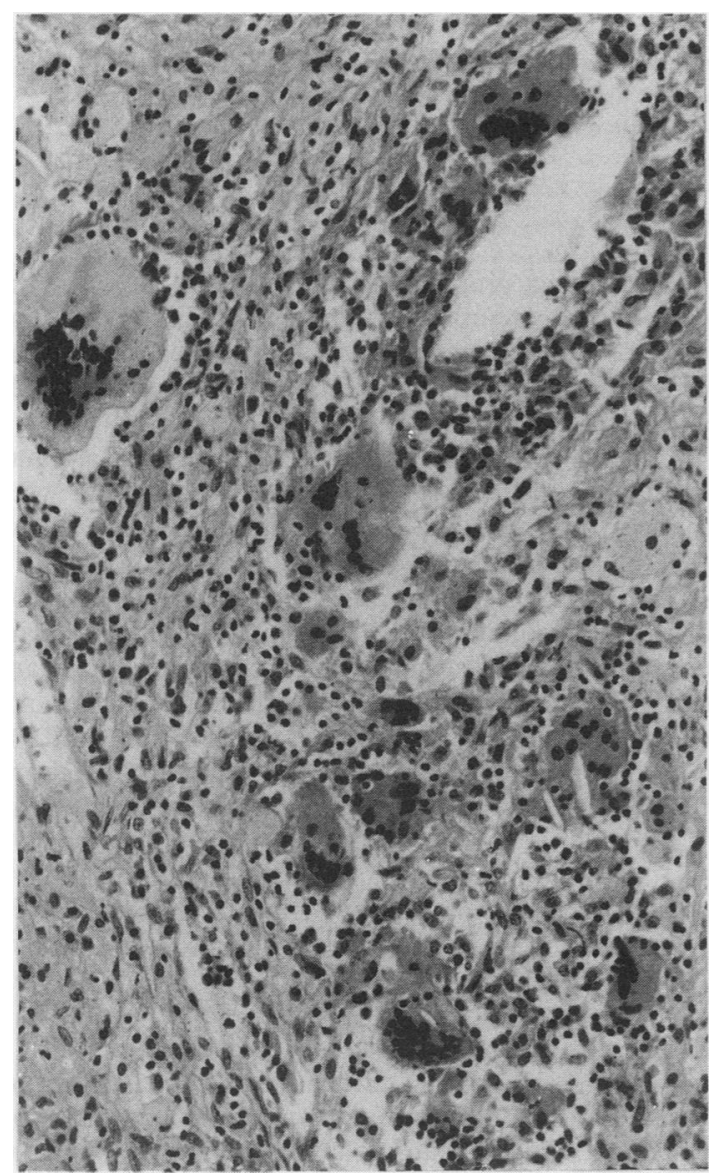

Fig 1 Case 1: giant cell granuloma set in fibrous stroma. (Haematoxylin and eosin.) $\times 280$. diameter uniform, cream coloured tumour which had no cystic areas, and was well demarcated from the surrounding testicular tissue. The gross appearance was thought to be that of a seminoma, because of the colour and homogeneity.

Microscopy showed broad islands and trabeculae of cells with open vesicular nuclei, multiple small dark nucleoli, clear cytoplasm and well defined cell borders. Moderate pleomorphism was seen, and five mitoses could be counted per high power field.

The tumour cells were once again set in a prominent fibrous stroma which contained a moderate infiltrate of lymphocytes (fig 4). There was a tendency for the tumour cells to surround microcystic spaces and show peripheral palisading (fig 5). A few tiny foci of yolk sac differentiation were seen, with an open reticular or lacy pattern. The yolk sac areas were closely associated with syncytial type giant cells, but no

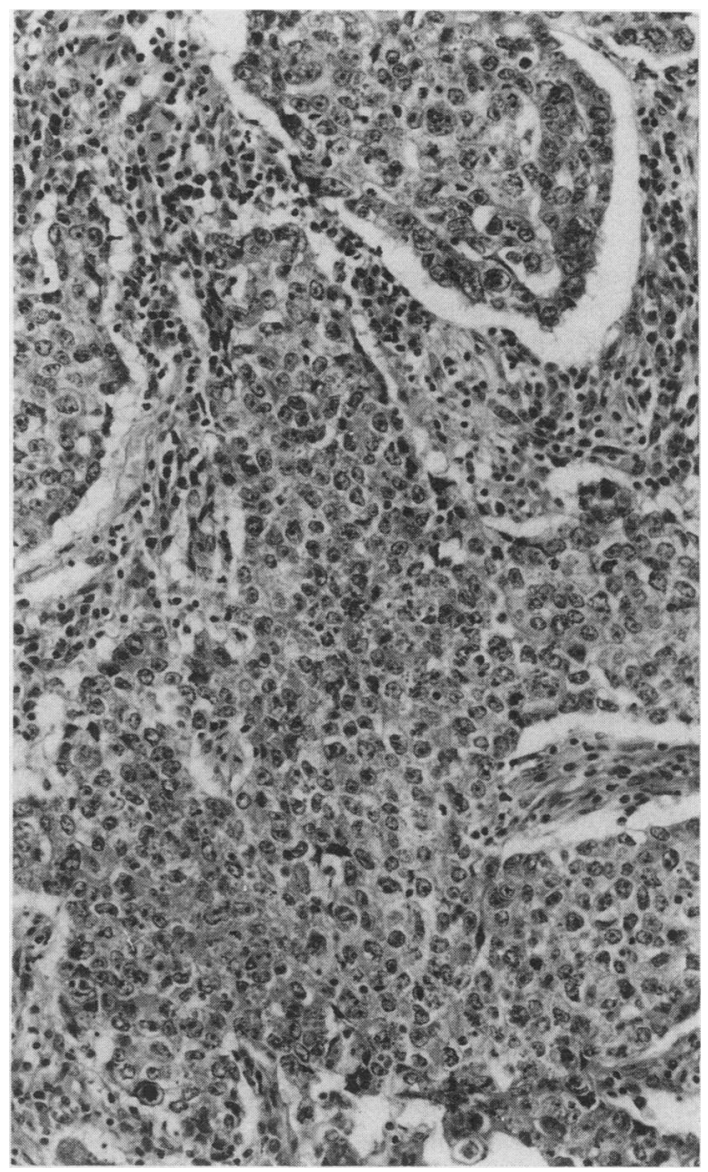

Fig 2 Case 1: seminoma like area. Broad islands of tumour cells set in fibrous stroma with associated lymphocytic infiltrate. (Haematoxylin and eosin.) $\times 260$. 


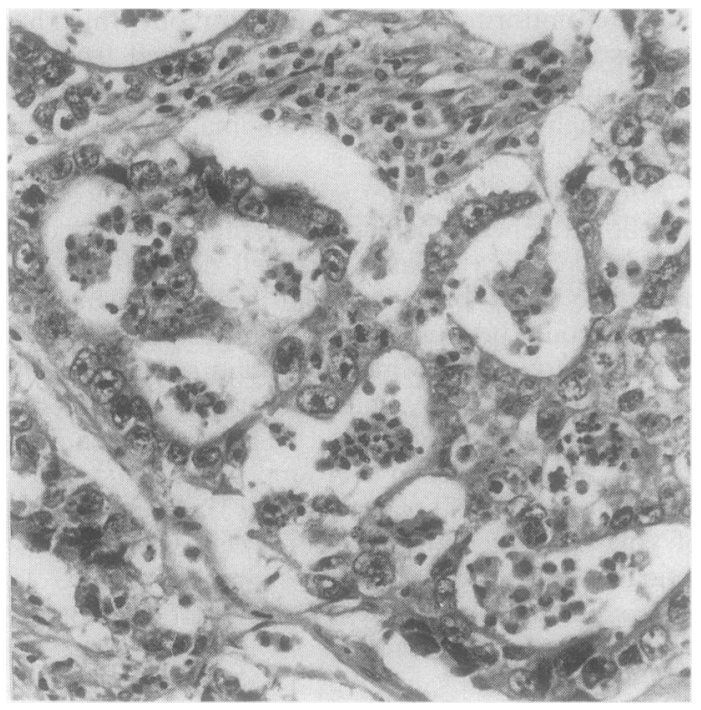

Fig 3 Case 1: more typical embryonal carcinoma, with tumour cells arranged around microcystic spaces.

(Haematoxylin and eosin.) $\times 280$.

cytotrophoblast was present.

The periodic acid Schiff technique failed to show any glycogen in the cells. Immunohistochemical staining with AFP outlined the areas of yolk sac differentiation (fig 6), with dark brown granular staining around lacy areas and cystic structures. BHCG staining was seen in giant cells lying in the fibrous stroma, but the CEA and cytokeratin stains were negative.

\section{Discussion}

These two cases illustrate the difficulty which can occasionally be encountered in distinguishing between embryonal carcinoma and seminoma, and the care the histopathologist must exercise to avoid making an erroneous diagnosis.

The tumours showed several features which could have pointed towards seminoma:

(i) They both had a prominent fibrous stroma containing lymphocytes and Langhans' giant cells.

(ii) In the first case ill defined granulomata were present.

(iii) The tumour cells had clear cytoplasm and well defined cell borders.

(iv) The cells were mostly arranged in circumscribed masses.

The World Health Organisation lists all these features as typical of seminoma, ${ }^{3}$ and states that lym-

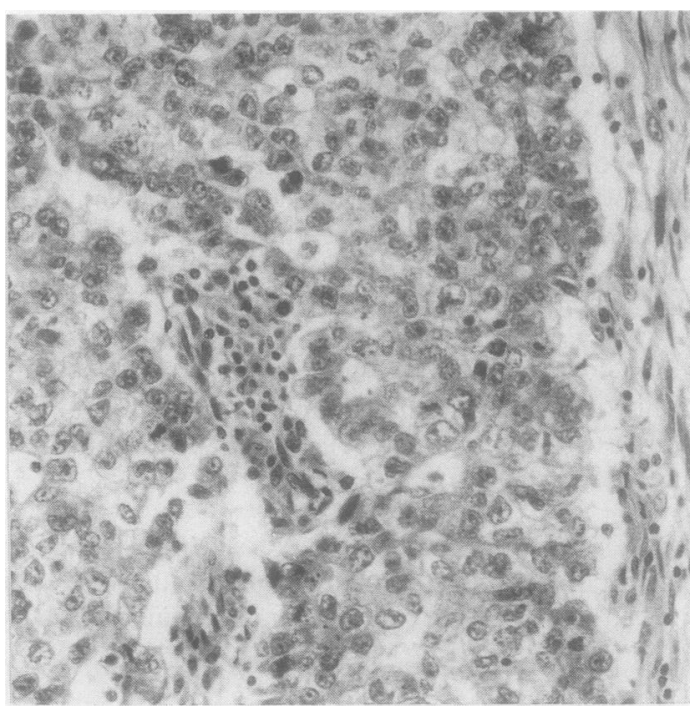

Fig 4 Case 2: seminoma like area. Broad islands of tumour cells set in fibrous stroma with associated lymphocytic infiltrate. (Haematoxylin and eosin.) $\times 260$

phocytic and granulomatous reactions are rare in embryonal carcinoma. It further suggests that the absence of lymphocytic stroma infiltrate is helpful in differentiating solid embryonal carcinoma which simulates seminoma. ${ }^{3}$

Despite the above contradictory findings a final confident diagnosis of embryonal carcinoma was made in both these cases. The findings which led to this diagnosis were:

(i) Although in some areas the tumour cells were arranged in solid masses like seminoma, there was an admixture of patterns typical of embryonal carcinoma, with both papillary and acinar areas, and cells orientated around cystic structures (figs 3 and 5). (ii) The tumour cells showed much greater pleomorphism than seen in seminoma, and the mitotic count was high.

(iii) Seminoma cells contain varying amounts of glycogen. ${ }^{45}$ This is reflected by periodic acid Schiff positivity of the tumour cells, which is said to be helpful in identifying seminoma. ${ }^{6}$ The tumour cells in these two cases showed no periodic acid Schiff positivity, despite the pale appearance of the cytoplasm.

(iv) Areas of yolk sac differentiation were present in the second case. Embryonal carcinoma is often associated with microfoci of yolk sac, but extraembryonic differentiation would be very rare in a seminoma without any teratomatous elements.

(v) The immunohistochemical findings of positive 


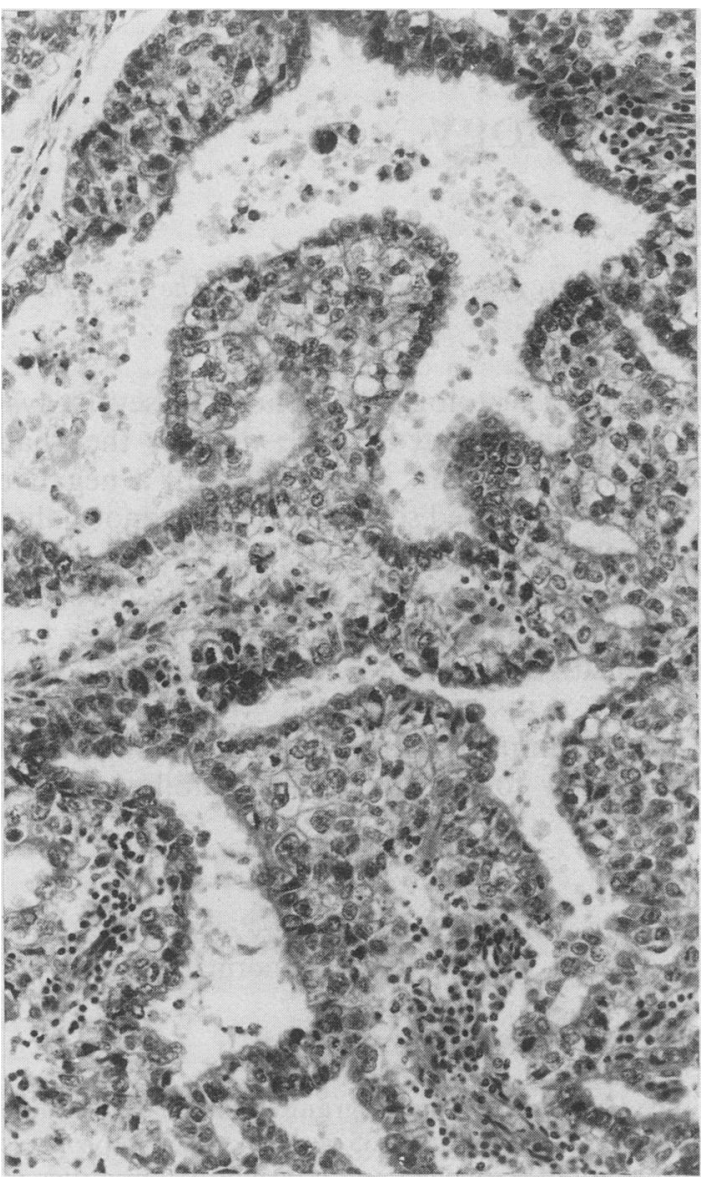

Fig 5 Case 2: more typical embryonal carcinoma with tumour cells arranged around microcystic spaces.

(Haematoxylin and eosin.) $\times 260$.

CEA in case 1 and positive AFP in case 2 are not in keeping with seminoma, which should be negative for both stains.

Another possibility considered was that these patients had combined tumours, with both seminoma and embryonal carcinoma present, but although the pattern varied, the cell type was the same throughout the tumour. In view of the variable appearance of the tumours it is, of course, mandatory that these malignancies are extensively sampled so that all elements are represented histologically.

The study of these cases has shown that solid embryonal carcinoma can closely simulate seminoma in both gross and histological appearance. Pathological criteria for diagnosis should be broadened, and

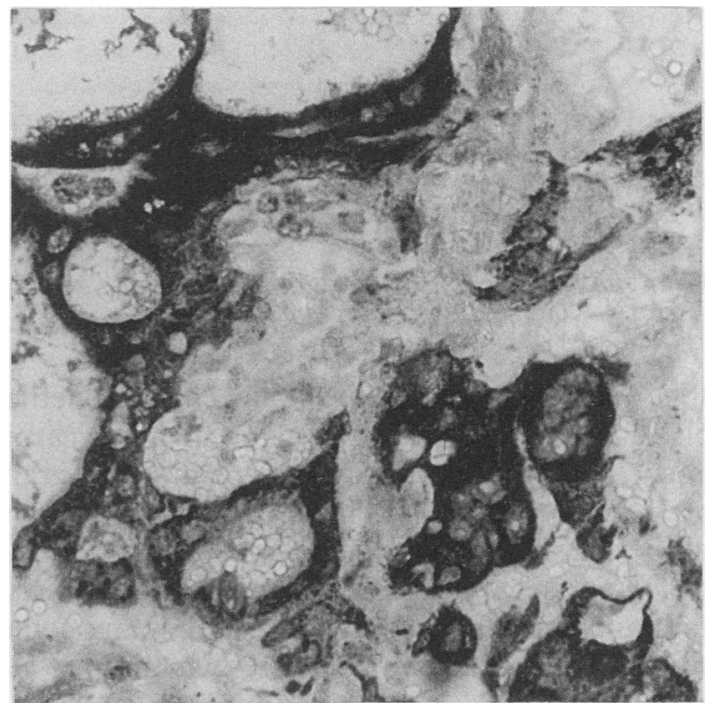

Fig 6 Case 2: AFP outlining area of yolk sac differentiation. (Immunoperoxidase.) $\times 360$.

our awareness of the area of overlap heightened so as to avoid misdiagnosis.

We are grateful to Mr Shasktri, FRCS, for providing necessary clinical information. We also thank the MLSO and secretarial staff of the histopathology department for their assistance.

\section{References}

1 Pierce GB, Abell MA. Embryonal carcinoma of the testis. New York: Appleton-Century Crofts, 1970:27-60.

2 Nakane PK, Pierce GB. Enzyme labelled antibodies: preparation and application for the localization of antigens. $J$ Histochem Cytochem 1966;14:929-31.

3 Mostofi FK, Sobin LH. Histological typing of testicular tumours. In: International histological classification of tumours, No 16. Geneva: World Health Organisation, 1977:27-31.

4 Pierce GB. Ultrastructure of human testicular tumours. Cancer 1966;19:1963-83.

5 Schulz L, Holstein AF. On the histology of human seminoma: development of the solid tumour from intratubular seminoma cells. Cancer 1977;39:1090-100.

6 Richter HJ, Leder LD. Lymph node metastases with periodic acid Schiff positive tumour cells and massive epithelioid granulomatous reaction as diagnostic clue to occult seminoma. Cancer 1979;44:245-9.

Requests for reprints to: Dr Joan M Alderdice, Department of Histopathology, The Laboratories, Belfast City Hospital, Belfast, BT9 7AD, Northern Ireland. 